\title{
Unusual pathological fracture of the clavicle revealing primary hyperparathyroidism: a case report
}

\author{
Yassir Benameur*, Hasnae Guerrouj, Imad Ghfir and Nouzha Ben Rais Aouad
}

\begin{abstract}
Background: Primary hyperparathyroidism revealed by a pathological fracture is very uncommon; in the majority of cases the discovery of lytic bone lesions on imaging examinations evokes in the clinician first a neoplastic etiology and a metabolic origin is often omitted. This case report adds to the existing literature as it describes an unusual presentation of primary hyperparathyroidism.

Case presentation: We report a case of a 50-year-old Moroccan man, without any known tumor, who presented a fracture of his left clavicle with multiple osteolytic lesions on computed tomography suggesting bone metastases. However, bone scintigraphy oriented the diagnosis to a metabolic pathology by showing a metabolic bone "super scan" with increased tracer uptake in the left clavicle; parathyroid scintigraphy was able to localize pathological right parathyroid tissue.
\end{abstract}

Conclusions: Whenever multiple osteolytic lesions are found in a patient without any known tumor, metabolic bone diseases including hyperparathyroidism should be highly considered.

Keywords: Primary hyperparathyroidism, Bone scintigraphy, Parathyroid scintigraphy, Pathological fracture, Osteolytic bone metastases

\section{Background}

Primary hyperparathyroidism (PHPT) is usually diagnosed as in incidental finding of raised serum calcium or due to symptoms secondary to the hypercalcemia such as polyuria, polydipsia, muscle weakness, gastrointestinal upsets, and renal stone formation [1].

The occurrence of bone lesions such as pathologic fractures in PHPT is now very rare since methods to measure serum calcium became available routinely in the mid-1970s [2].

We report a case of PHPT revealed by a pathological fracture of the left clavicle, associated with multiple osteolytic lesions which were initially confused with bone metastases. Bone scintigraphy oriented the diagnosis to a metabolic bone disease; elevated serum calcium and parathyroid hormone (PTH) confirmed the diagnosis of PHPT.

\footnotetext{
* Correspondence: Benameur.yassir@gmail.com; benameur.yassir@gmail.com Department of Nuclear Medicine, Ibn Sina Hospital, Mohammed V University, Rabat, Morocco
}

\section{Case presentation}

A0-year-old Moroccan man presented to our orthodepartment after tripping on a step and falling his left side. He had a 4-year history of type 2 diabestension. His medication included furosemide, captopril, and metformin. He had a tobacco ing approximately 5 years ago.

A review of his social and environmental history did not indicate exposure to any other known toxins or carcinogens. He denied any family history of cancer. He is a police officer and he lives with his wife and two children. 
A physical examination revealed a blood pressure at $135 / 80 \mathrm{mmHg}$, a normal pulse rate, and no fever; he had no symptoms except for the left clavicular pain.

Radiographs showed a lytic lesion in his left clavicle and an asymptomatic lytic lesion in the left humeral head. A computed tomography (CT) scan was performed and objectified multiple osteolytic lesions on the whole skeleton (Fig. 1).

A neoplastic origin was first suspected; our patient was then referred to our nuclear medicine department with suspected bone metastases.

A whole-body bone scintigraphy with technetium-99m $\left({ }^{99 \mathrm{~m}} \mathrm{Tc}\right)$-methylene diphosphonate (MDP) was particularly interesting insofar as it was able to orient the diagnosis to a metabolic bone disease. It demonstrated diffusely increased uptake in both axial and appendicular skeleton, absent urinary activity, and prominent calvarian and periarticular uptake, with a focal accumulation of radiotracer on the left clavicle (Fig. 2).

His complete blood count hemoglobin level was $15 \mathrm{~g} / \mathrm{dl}$, white cell count at 8900, and platelet count at 170,000; his transaminases and his serum electrolytes were normal. Hepatitis A serology, hepatitis B serology, hepatitis $\mathrm{C}$ serology, and human immunodeficiency virus (HIV) serology were also negative.

Laboratory studies also revealed an elevated serum calcium level of $3.8 \mathrm{mmol} / \mathrm{l}$ (corrected range, 2.15 to 2.60 ) and a circulating level of PTH of $1905 \mathrm{pg} / \mathrm{ml}$ (normal range, 14 to 72 ), his creatinine level was within normal limits. The diagnosis of PHPT was then confirmed.

Considering possible hyperparathyroidism caused by a parathyroid nodule, a cervical ultrasound was done and identified an adenoma in the right inferior parathyroid gland; this was confirmed by a parathyroid scintigraphy with ${ }^{99 \mathrm{~m}}$ Tc-methoxyisobutylisonitrile (MIBI) using washout method, which showed a focal increased uptake in inferior right parathyroid gland (Figs. 3 and 4).

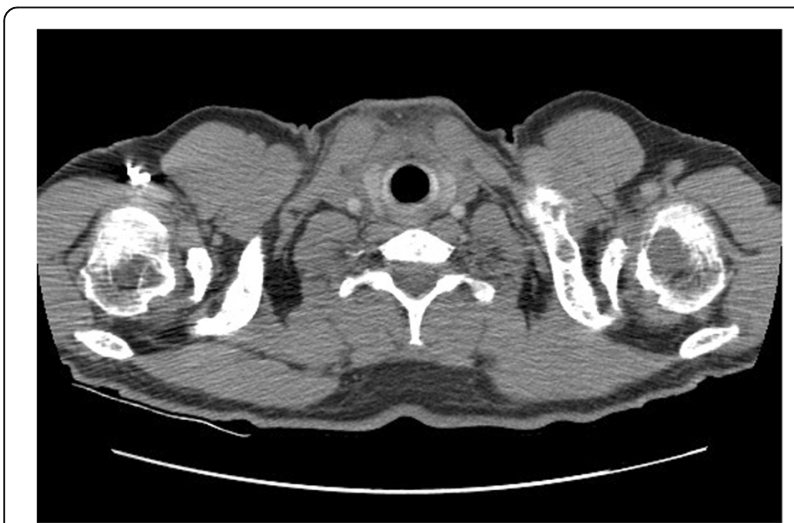

Fig. 1 Thoracic computed tomography showing lytic lesions of the left clavicle and left humeral head and multiple lacunar foci

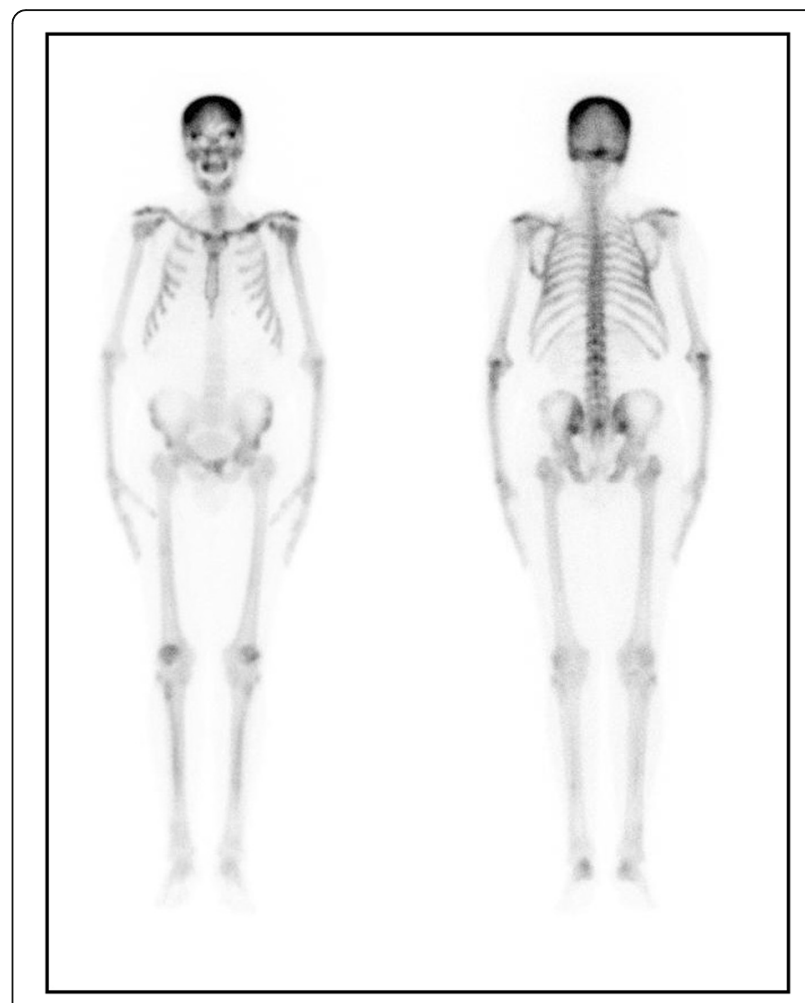

Fig. 2 Bone scintigraphy with technetium-99m-methylene diphosphonate demonstrating diffusely increased uptake in both axial and appendicular skeleton, absent urinary activity, and prominent calvarian and periarticular uptake, with a focal accumulation of radiotracer on the left clavicle indicative of a metabolic bone disease

A parathyroidectomy was performed and a large parathyroid tumor was removed and confirmed to be a benign parathyroid adenoma on histological examination.

After surgery, our patient's PTH level returned to normal but he developed hypocalcemia, requiring doses of orally administered calcium. He was alive and showed no symptoms during a 6-month follow-up period.

\section{Discussion}

Before undergoing the bone scintigraphy, our patient was suspected to have bone metastases. Fortunately, the bone scan demonstrated an aspect of metabolic disease; his serum calcium and PTH levels led to the correction of the diagnosis to PHPT.

This case highlights that pathological fracture is not always synonymous with cancer, several differential diagnoses must be taken into consideration, among them PHPT.

PHPT is a relatively common endocrine disorder, with prevalence estimates of one to seven cases per 1000 adults. It is believed to be the most common cause of hypercalcemia, predominantly affecting elderly populations and women two to three times as often as men. The incidence of PHPT has been difficult to assess, 


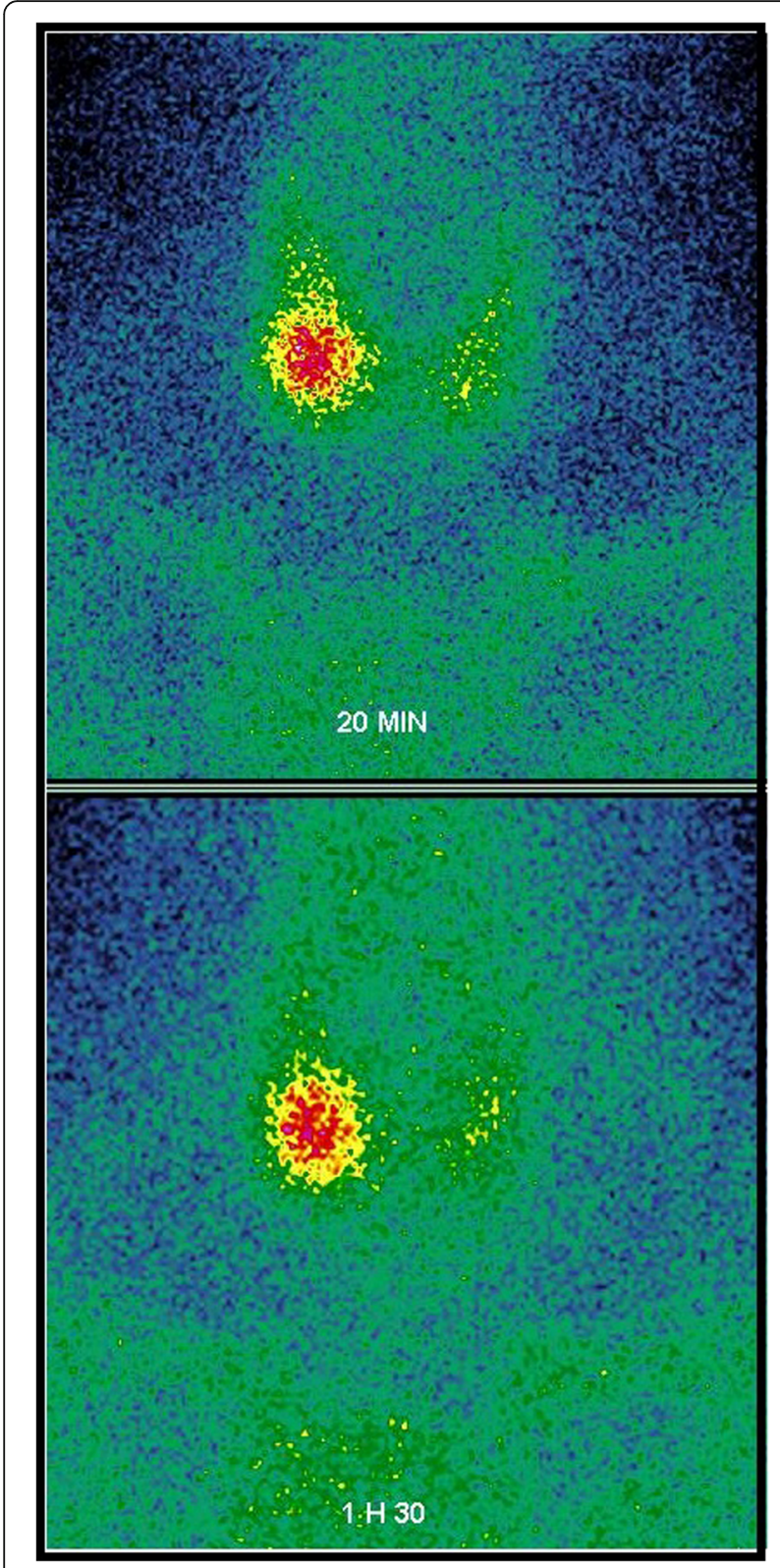

Fig. 3 Parathyroid scintigraphy with technetium-99m methoxyisobutylisonitrile using washout method evoked pathological right parathyroid tissue

available estimates vary widely from 0.4 to 21.6 cases per 100,000 person-years [3].

In most patients with PHPT (80 to $85 \%$ ), the disease develops due to a parathyroid adenoma, in 15 to $20 \%$ due to parathyroid gland hyperplasia, and in $<0.5 \%$ due to parathyroid carcinoma [4].

Many cases of PHPT are diagnosed in the early stages of the disease process, before the development of classical clinical findings of prolonged disease such as nephrolithiasis, brown tumors or osteitis fibrosa cystica, bone cysts, or pathologic fracture. Early diagnosis has

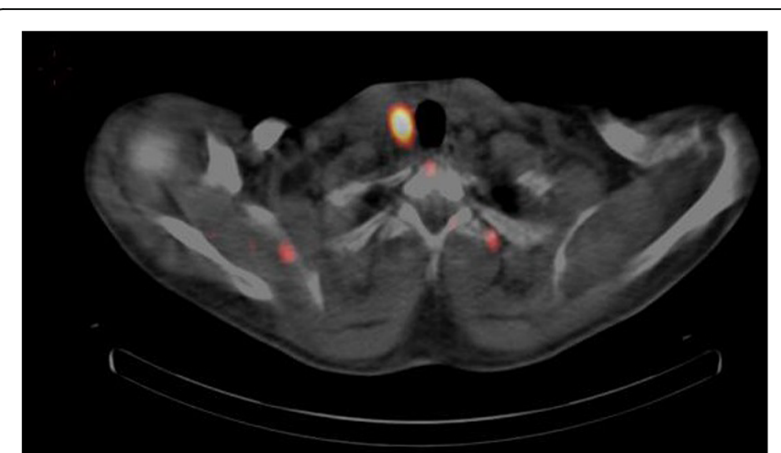

Fig. 4 Axial fused cervical single-photon emission computed tomography/computed tomography image showing pathological right parathyroid tissue

resulted in a significant decline in what were once the common morbidities of the disease [5].

The incidence of pathological fractures in PHPT is relatively rare accounting for around $10 \%$ in two large series [6]. However, PHPT revealed by pathological fracture, as in our case, is very uncommon.

Morgan et al. reported a case of subtrochanteric fracture of the femur through an area of lytic bone with hypercalcemia which was felt to be a metastatic pathological fracture [7], the same presentation was found in the case reported by Khaoula et al. [2]. Rachha also reported three cases which involved the long bones [1].

A literature review of other reported cases using the PubMed database revealed that our case is the first presentation of PHPT revealed by clavicle fracture.

A cancerous origin is suspected before a pathological fracture with multiple lytic bone lesions; this was the situation in our patient, who underwent skeletal scintigraphy to look for bone metastases. However, fortunately, the bone scan showed a feature of metabolic bone disease. With metabolic bone disease there is a generalized increased uptake throughout the skeleton and markedly reduced soft tissue background activity. The kidneys appear faint or there may be absence of the normal renal activity, giving the "super scan" because of the predominance of the bone images [8]. PHPT is one of the main etiologies of this feature on bone scintigraphy. Other skeletal anomalies secondary to hyperparathyroidism are also possible and are detailed in Table 1 [9-12].

Once the diagnosis of PHPT is confirmed by increased serum PTH level, parathyroid localization studies such as neck ultrasound scan and ${ }^{99 \mathrm{~m}} \mathrm{Tc}$-MIBI scintigraphy are used to confirm the location of the diseased gland rather than for establishing the diagnosis of PHPT preoperatively.

Initially, ${ }^{99 \mathrm{~m}}$ Tc-MIBI is concentrated in the thyroid gland and abnormal parathyroid tissue and then differentially clears from these organs in a time-dependent manner; washout of the thyroid gland is more rapid than 
Table 1 All skeletal and extraskeletal anomalies secondary to hyperparathyroidism

\begin{tabular}{ll}
\hline Skeletal & Early stage: \\
anomalies & - Symmetrical abnormal bone activity is present, particularly \\
& in the calvarium, mandible, sternum, and epiphyses of long \\
bones with or without accompanying changes in the & \\
& vertebrae and pelvis [9]. \\
& Severe cases: appearances are those of a super scan: \\
& - Increased tracer uptake in axial skeleton. \\
& - Increased tracer uptake in long bones. \\
& - Increased tracer uptake in periarticular areas. \\
& - Faint or absent kidney images [10]. \\
Extraskeletal & Extraskeletal metastatic calcification in primary \\
anomalies & hyperparathyroidism: \\
& - Increased visceral uptake of technetium-99m-labeled \\
& phosphate throughout the lung, liver, stomach [11]. \\
& Extraskeletal anomalies secondary to secondary \\
& hyperparathyroidism: \\
& - Increased diffuse activity in the lungs and the small \\
kidneys. & \\
& - Increased muscle activity (diffuse and bilaterally in the \\
& vast and adductor of both thighs, and in the abdominal \\
& muscles) [12].
\end{tabular}

from the abnormal parathyroid tissue that allows dualphase ${ }^{99 \mathrm{~m}}$ Tc-MIBI scintigraphy to detect the hyperfunctioning parathyroid tissue [5].

Parathyroidectomy is the treatment of choice in PHPT. In the last 10 to 15 years, surgery for PHPT has moved from the wide bilateral neck exploration to minimally invasive approaches, such as the minimally invasive radioguided parathyroidectomy [13].

\section{Conclusions}

This case illustrates a rare presentation of a parathyroid adenoma revealed by clavicle fracture, and highlights the importance of explorations using nuclear medicine. When a patient presents with unexplained osteolytic lesions, although metastatic malignancies should be ruled out first, other differential diagnoses such as metabolic bone disease including hyperparathyroidism should be kept in mind as well, in order to reach an accurate diagnosis.

\section{Abbreviations \\ ${ }^{99 m}$ Tc: Technetium-99m; CT: Computed tomography; HIV: Human immunodeficiency virus; MDP: Methylene diphosphonate; \\ MIBI: Methoxyisobutylisonitrile; PHPT: Primary hyperparathyroidism; PTH: Parathyroid hormone}

\section{Acknowledgements}

None.

\section{Funding}

None.

\section{Availability of data and materials}

Not applicable.

\section{Authors' contributions}

BY analyzed and interpreted the patient data, drafted the manuscript, and made the figures. $\mathrm{GH}, \mathrm{Gl}$, and BRAN proposed the study, supervised, and revised the manuscript. All authors read and approved the final manuscript.
Ethics approval and consent to participate

Not applicable.

\section{Consent for publication}

Written informed consent was obtained from the patient for publication of this case report and any accompanying images. A copy of the written consent is available for review by the Editor-in-Chief of this journal.

\section{Competing interests}

The authors declare that they have no competing interests.

\section{Publisher's Note}

Springer Nature remains neutral with regard to jurisdictional claims in published maps and institutional affiliations.

Received: 12 July 2017 Accepted: 7 November 2017

Published online: 09 December 2017

\section{References}

1. Rachha R. Pathological fractures as the presenting symptom of parathyroid adenoma: a report of three cases. BJMP. 2008;1(1):26-9.

2. Khaoula BA, Kaouther BA, Ines C, Sami T, Zakraoui L, Khedher A. An unusual presentation of primary hyperparathyroidism: pathological fracture. Case Rep Orthop. 2011;2011:521578.

3. Yeh MW, Ituarte PH, Zhou HC, Nishimoto S, Liu IL, Harari A, et al. Incidence and prevalence of primary hyperparathyroidism in a racially mixed population. J Clin Endocrinol Metab. 2013;98(3):1122-9.

4. Huang R, Zhuang R, Liu Y, Li T, Huang J. Unusual presentation of primary hyperparathyroidism: report of three cases. BMC Med Imaging. 2015;15:23.

5. Nevena R, Sinisa S, Daniela PG, Meri A. Scintigraphic evaluation of multifocal osteolytic lesions in a patient with primary hyperparathyroidism: A case report. Iran J Nucl Med. 2015;23(2):134-8.

6. Sahu PK, Galagali JR, Singh ID, Kumar S. A large parathyroid adenoma presenting with pathological fractures in a young male. Int J Otorhinolaryngol Head Neck Surg. 2015;1:88-92.

7. Morgan G, Ganapathi MS, Afzal S, Grant AJ. Pathological fractures in primary hyperparathyroidism: a case report highlighting diagnostic difficulties. Injury. 2002;33(3):288-91.

8. Hain SF, Fogelman I. Nuclear medicine studies in metabolic bone disease. Semin Musculoskelet Radiol. 2002;6(4):323-9.

9. Sy WM. Bone Scan in Primary Hyperparathyroidism. J Nucl Med. 1974;15: 1089-91.

10. Fogelman I, Bessent RG, Turner JG, Citrin DL, Boyle IT, Greig WR. The use of whole-body retention of $\mathrm{Tc}-99 \mathrm{~m}$ diphosphonate in the diagnosis of metabolic bone disease. J Nucl Med. 1978;19:270-5.

11. Hwang GJ, Lee JD, Chang Yun Park CY, Lim SK. Reversible extraskeletal uptake of bone scanning in primary hyperparathyroidism. J Nucl Med. 1996;37:469-71.

12. Sy WM, Mottola O, Lao RS, Smith A, Freund HR. Unusual bone images in hyperparathyroidism. Br J Radiol. 1977;50:740-4.

13. Hussain A, Mahmood H, Geddoa E, Hamish M, Reda AH. Parathyroid adenoma and hypercalcemia in a patient presenting with multiple pathological fractures of the long bones. Int J Surg. 2008:6:465-8.

Submit your next manuscript to BioMed Central and we will help you at every step:

- We accept pre-submission inquiries

- Our selector tool helps you to find the most relevant journal

- We provide round the clock customer support

- Convenient online submission

- Thorough peer review

- Inclusion in PubMed and all major indexing services

- Maximum visibility for your research

Submit your manuscript at www.biomedcentral.com/submit 